\title{
AS HISTÓRIAS EM QUADRINHOS COMO FENÔMENO LITERÁRIO: PROBLEMAS, IMPASSES E DESAFIOS
}

\author{
Renan Duarte * \\ Anderson Pires da Silva**
}

RESUMO: Este trabalho tem como intenção discutir questões suscitadas pelo entendimento das histórias em quadrinhos como fenômeno literário. A princípio, buscamos compreender como as HQs se aproximaram do campo da literatura, considerando as proposições de Eisner (1989) sobre narrativas dos quadrinhos como arte sequencial e a popularização da ideia de romance gráfico. Discutimos então, a partir de teóricos como Beaty (2012), Hatfield (2010) e Groensteen (2015), sobre as tensões que emergem no campo teórico, entre a definição de quadrinhos como literatura ou arte visual, e os impasses causados pela busca de prestígio, além de questões sobre o próprio campo dos estudos sobre quadrinhos como uma disciplina própria.

PALAVRAS-CHAVE: História em quadrinhos; Literatura; Romance gráfico.

\section{Introdução}

Que as histórias em quadrinhos (HQs) hoje são parte integrante da cultura contemporânea é um fato consumado. Originários do final do século XIX, os quadrinhos, ou the funnies (como eram conhecidos nos EUA), ganharam espaço nas páginas dos jornais (MOYA, 1970). Sem muitas pretensões, as tiras e pranchas incorporavam influências temáticas e estéticas dos populares shows de variedades e dos cartuns e caricaturas da época, como demonstra Mary Wood (2014) ao analisar a obra de Richard Outcault, um dos artistas pioneiros e criador do icônico Yellow Kid, em sua série Hogan's Alley. Com o tempo, os

\footnotetext{
* Doutorando em Estudos Literários pela Universidade Federal de Juiz de Fora (UFJF). Mestre em Estudos Literários pela mesma Instituição. Desenvolve pesquisa sobre Histórias em Quadrinhos, mais especificamente sobre o gênero tira, suas vertentes, temáticas, formas e métodos de composição, além das relações dos estudos sobre histórias em quadrinhos com outros campos do saber.

** Doutor em Letras pela Pontifícia Universidade Católica do Rio de Janeiro (Puc-RJ). Professor adjunto da Faculdade de Letras da Universidade Federal de Juiz de Fora (UFJF). É autor dos seguintes livros: "Malditos” (Penalux, 2018), “Trovadores elétricos” (Funalfa/Aquela Editora - 2012), "Mário e Oswald: uma história privada do modernismo" (Faperj/7letras - 2009), e coautor de "Livro de setes faces" (Funalfa/Nankin - 2006).
} 
quadrinhos tornaram-se mais articulados e passaram a não somente adotar uma série de procedimentos de outras mídias, como também a inventar outros. Tornaram-se, portanto, uma arte complexa, que compartilha sua linguagem com as mais variadas vertentes artísticas como a música ou a literatura, tal qual aponta Daniele Barbieri (2017), em As linguagens dos quadrinhos, ao afirmar que os quadrinhos atravessam e são atravessados por muitas linguagens.

No entanto, mesmo sendo influenciadas por temáticas, formas e procedimentos de outras artes, as histórias em quadrinhos nunca foram legitimadas - ao menos até um pouco mais da metade do século passado - como uma forma de arte cujo status gozasse de mesmo prestígio daquelas nas quais se inspiram. Isso devido também ao fato de fazerem parte do surgimento de uma nova forma de cultura na modernidade: a cultura de massa. Sobre o impacto da cultura de massa no campo da teoria da arte, Walter Benjamin (1993) argumentava que o cinema e as novelas de rádio (assim como as HQs), para atender uma demanda de massa, deixavam de lado "numerosos conceitos tradicionais - como criatividade e gênio, validade eterna e estilo, forma e conteúdo" (BENJAMIN, 1993, p. 174).

Além disso, por estarem longe de ocupar um espaço de credibilidade, os estudos sobre essa mídia também não poderiam esperar tratamento diferente. O que nos espanta, e ao mesmo tempo anima, é o fato de os estudos literários durante tanto tempo não terem considerado as HQs como objeto de análise, mesmo com pesquisas no campo da Educação apontando para o fato de os gibis serem a porta de entrada para o mundo da leitura de ficção, principalmente entre as camadas de baixa renda (RAMA; VERGUEIRO, 2004).

Houve sinalizações no sentido de se compreender as HQs como fenômeno não somente da cultura de massa, como também literário. E esses sinais partiram dos próprios teóricos dos quadrinhos. Para Will Eisner (1999), as histórias em quadrinhos combinam as regências da arte (simetria, perspectiva, pincelada) e da literatura (enredo, gramática, sintaxe). Jean-Bruno Renard (1978) aprofunda a comparação, dizendo que "as HQs estão mais 
próximas da literatura do que do cinema" (RENARD, 1978, p. 11 , tradução nossa) ${ }^{1}$, constituindo um objeto - a revista em quadrinhos - que obedece a uma ordem de leitura igual, na maioria dos casos, à literária (da esquerda para direita); o leitor reconstitui em sua mente os sons e os movimentos dos personagens, possibilitando um tipo de percepção semelhante à da leitura de um livro, ao poder demorar o tempo que achar necessário numa página ou voltar atrás (RENARD, 1978), por exemplo. Assim, a fim de justificar o interesse acadêmico pelo objeto, parte dos estudiosos e autores optou por rotulá-lo como algo que, além de não precisar de justificativa alguma, goza do mais alto prestígio: a literatura (afinal, se quadrinhos não são dignos da mesma atenção de outras artes, então deveriam ser entendidos como integrante de algo que o seja).

Porém, esses argumentos foram muito mal compreendidos pela crítica literária e a comunidade acadêmica, pois se entendia que por "fenômeno literário" se pretendia considerar as histórias em quadrinhos como literatura. Coisa inaceitável, uma expressão popular destituída de "aura artística" se equiparar à "aura" da literatura e o seu objeto, o livro. Como apontava Benjamin (1993), cujo pensamento ampliamos, as HQs como fenômeno literário provocam transformações radicais nos conceitos tradicionais de literatura.

Para alguns estudiosos, a definição de quadrinhos como literatura gerou certos impasses que refletiram na dificuldade dos estudos sobre essa arte se estabelecerem como uma disciplina autêntica. Para outros, contribuiu para rever os conceitos tradicionais e retrógrados de literatura. Há ainda os que acreditam que o debate está superado e a associação com a literatura foi apenas uma fase. Nesse sentido, este artigo busca rever essa questão a partir da atual perspectiva dos estudos sobre quadrinhos, buscando enxergar e compreender o que ainda está em debate. 


\section{Porta de entrada: quadrinhos como leitura e literatura}

Se compararmos o desenvolvimento dos estudos acadêmicos sobre outras artes tão jovens quanto os quadrinhos, perceberemos uma diferença considerável. Thierry Groensteen (2009) destaca o fato de que, na França, entre a publicação, em 1845, de Essai de Physiognomonie ${ }^{2}$, e uma nova tentativa de abordar o tema, em 1955, com a publicação de Le Petit Monde de Piflechien, de Barthélémy Amengual, há uma distância de 110 anos, enquanto livros sobre cinema e fotografia eram comumente publicados (GROENSTEEN, 2009). A diferença de tratamento explica-se pela própria compreensão do que pode ser considerado como digno de atenção - algo que custou aos quadrinhos um tempo maior.

Hoje, os estudos sobre quadrinhos estão em ascensão e não demonstram resistência em acolher diferentes abordagens dos mais variados grupos e disciplinas. Destacamos a edição n 215 da revista Cult, publicada em agosto de 2016, seção "Literatura", sobre as graphic novels - cujo título "A ascensão do romance gráfico" é uma clara alusão ao canônico estudo Ascensão do romance de Ian Watt. O organizador do dossiê, Manuel da Costa Pinto (2016), argumentava:

Este especial da CULT aborda o mais novo dos gêneros literários: a graphic novel ou romance gráfico, uma de suas possíveis denominações [...]. Como gênero que nasceu pelas mãos de um mestre da Era de Ouro dos quadrinhos e que é contemporâneo da era não menos dourada da teoria literária (os anos 1970, com estruturalismo e pósestruturalismo arrematando um século que reivindicou para a crítica literária o status de gênero literário de não ficção), a graphic novel[...] é a contrapartida visual do romance e pertence a uma linguagem mais geral - os quadrinhos - que surge na esteira de um período no qual as vanguardas (de Apollinaire aos concretos) exploraram a visualidade da palavra [...]. (PINTO, 2016, p. 52).

Todavia, o processo histórico que marginalizou tanto os interesses acadêmicos quanto o próprio objeto resultou na dificuldade de se estabelecer uma disciplina própria do meio, capaz de fornecer aparatos críticos e teóricos distintos. Charles Hatfield (2010),

2 Obra de Rudolff Töpffer que, segundo o autor, estabelece as fundações de uma teoria dos quadrinhos. 
estudioso norte-americano dos quadrinhos, identifica que o campo sofreu da falta de coerência e não goza do mesmo status de uma disciplina em seu sentido mais tradicional. Afirma ainda:

O que torna a questão mais aguçada para os estudos em quadrinhos é que o próprio surgimento do campo exigiu uma série de parcerias interdisciplinares ad hoc que até agora não foram objeto de reflexão crítica. Para atingir uma massa crítica intelectual e profissionalmente, os estudos em quadrinhos tiveram que ter uma perspectiva multidisciplinar, mas a sobreposição e a tensão entre as várias disciplinas participantes ainda não levaram a uma discussão acordada, muito menos a um modelo coerente de interdisciplinaridade. (HATFIELD, 2010, p. 3, tradução nossa). ${ }^{3}$

Depois de uma década desta constatação do autor, sua posição sobre a necessidade de se pensar o próprio campo dos quadrinhos enquanto disciplina ainda é pertinente. De que maneira, na urgência supracitada, os métodos das Letras se aproximaram do estudo dos quadrinhos é o que nos interessa aqui; voltemos, portanto, a essa questão.

Para compreendermos essa aproximação, é preciso retroceder um pouco para identificarmos quais ideias a justificam. Certamente há outros interesses que fogem de nosso panorama, mas vamos nos deter em dois pontos principais. Primeiro, a ideia dos quadrinhos como leitura (disputando, com ela, o mesmo campo de função enquanto ferramenta pedagógica). E, como desdobramento, os quadrinhos como literatura. Ambas as associações serviram como justificativa para que os estudiosos dos quadrinhos enxertassem teorias linguísticas e dos estudos literários em suas análises (GROENSTEEN, 2015).

Grande parte da história da nona arte 4 foi marcada pela compreensão de que se tratava de uma mídia para crianças, o que pode explicar o pouco interesse ou descrédito

\footnotetext{
3"What makes the question acute for comics studies is that the field's very emergence has required a series of ad hoc cross-disciplinary partnerships that have not thus far been subject to critical reflection. In order to reach critical mass intellectually and professionally, comics studies has had to take a multidisciplinary perspective, yet the overlap and tension between the various participating disciplines has not yet led to a concerted discussion, much less a coherent model, of interdisciplinarity."

${ }^{4}$ Dando continuidade à classificação clássica das sete artes, as Histórias em Quadrinhos são hoje conhecidas também como a nona arte. $\mathrm{O}$ termo tem sua origem em um artigo do crítico de cinema Claude Beylie (“La bande dessineé est-elle un art?’), de 1964 (CAMPOS, 2015).
} 
por parte dos acadêmicos, o que implica em apontar o caráter pré-conceitual dos estudos literários no Brasil. Afinal, algo do interesse exclusivo de crianças não poderia ser levado a sério - pelo menos, não por pessoas que tratavam apenas de assuntos “elevados”. Esse preconceito se estendeu a ações que visavam legitimar os quadrinhos como literatura, como o citado dossiê da revista Cult, que privilegiou um determinado estilo de HQs, a graphic novel, também denominada como "quadrinho adulto". Porém, antes os comics não eram necessariamente vistos como um objeto direcionado ao público infantil; a percepção mudou devido a alguns fatores que envolvem, principalmente, a associação das temáticas das HQs com o universo da infância - animais falantes, tiras protagonizadas por crianças, etc. (DUARTE, 2018; SANDERS, 2016). A descoberta da criança como leitora e o surgimento de um tipo de literatura específico para ela data do século XIX, sendo uma ideia contemporânea ao surgimento das HQs, correspondendo a um sistema ficcional muito próprio. Tanto que no Brasil temos autores de literatura infantil que também são quadrinistas ou histórias em quadrinhos que constam da bibliografia obrigatória das escolas de ensino fundamental. Os exemplos mais evidentes são a obra de Ziraldo e de Maurício de Souza.

No entanto, o mercado a produz para o público infantil baseado na concepção reducionista de que as massas são, por natureza, infantilizadas e, logo, os produtos direcionados a elas também. Aos poucos, a compreensão geral, e até mesmo parte do próprio meio acadêmico, passou a idealizar os quadrinhos como algo para crianças e pré-adolescentes.

Estabelecida a ideia, não tardou para que as preocupações pedagógicas se apresentassem. Rogério de Campos (2015), em Imageria: o nascimento das histórias em quadrinhos, afirma que publicações contendo imprecisões sobre as HQs, desvalorizando sua leitura, seguiramse por pessoas que não apreciavam o meio e infundiam as mentes de pais e mestres que se tratava de um material contra os bons costumes, tendo como grande líder dessa empreitada 
Fredric Wertham, com seu livro sensacionalista Seduction of the Innocent, de 19545.Afirma Campos (2015):

\begin{abstract}
Wertham forneceu o fundamento pseudocientífico para uma suspeita que aterrorizava fazia tempo as famílias norte-americanas: a de que os quadrinhos eram os culpados por suas doces crianças estarem se transformando em delinquentes juvenis.

Os quadrinhos deixaram naquele momento de ser tema para historiadores e passaram a ser caso de polícia. Naquele final dos anos 1940, entraram no momento mais difícil de sua história, combatidos ferozmente por educadores, psicólogos, padres, alarmistas profissionais da imprensa, políticos, guardiões da alta cultura, direitistas, stalinistas e moralistas de todo tipo como causa da delinquência juvenil, armas da subversão esquerdista, instrumentos de lavagem cerebral imperialista norte-americana, inimigos da educação, "uma desgraça nacional"'(segundo o crítico literário Sterling North), empecilho para a alfabetização das crianças, refugo da indústria cultural, "marijuana intelectual" (segundo Marya Mannes, editora da Vogue), porta de entrada para todos os vícios, "extremamente perigosos nas mãos de uma criança estável”'(segundo J. Edgar Hoover, o diretor do FBI), "veneno em forma de imagens para crianças"(segundo Louis $\mathrm{Pa}$ wels, que anos depois publicou quadrinhos na revista Planète), sementes da perversão sexual e, como costuma acontecer nesses momentos de histeria social no Ocidente, parte da conspiração comunista-judaica. (CAMPOS, 2015, p. 13).
\end{abstract}

O resumo de Campos (2015) sintetiza o cenário de depreciação em que os quadrinhos se encontravam diante da opinião pública nos EUA, o seu local de origem como leitura de massa e indústria cultural. O que se seguiu foi uma espécie de "caça às bruxas", uma corrida desesperada para extirpar as HQs do mundo dos filhos bem cuidados: queimas públicas, interrogatórios na Comissão de Investigação do Senado dos Estados Unidos, falência de editoras, artistas e roteiristas talentosos que mudaram completamente de ramo abandonando o ofício, além da criação de um código de autocensura (o Comics Code) pelo

${ }^{5}$ Wertham era psicólogo e desenvolvia uma pesquisa sobre o comportamento de jovens chamados "delinquentes". Seu campo de pesquisa fora as escolas públicas. Analisando os relatórios de acompanhamento acadêmico, focado nos discentes "problemáticos", concluiu que a grande maioria era leitora de histórias em quadrinhos. E mais, as HQs de Batman, Mulher-Maravilha e Cripta do Terror estimulavam comportamentos "desviantes" como a homossexualidade, o feminismo, o desrespeito às normas familiares e às figuras de autoridade. (MOYA, 1972, p. 70). 
próprio meio (CAMPOS, 2015; MOYA, 1970). Assim, na visão popular, os quadrinhos tornaram-se a antítese do que as "virtudes da leitura" poderiam representar.

Reverter esse quadro e ganhar a respeitabilidade cultural exigiu um movimento contrário - ou seja, inverter a narrativa e apostar na ideia de que quadrinhos podem ser leitura de alta qualidade. Para tanto, foi necessário o advento da idealização e popularização do que comumente chamamos de graphic novel, ou romance gráfico. O próprio termo já trazia em si a gênese do intento: associar quadrinhos ao romance e, por conseguinte, ao prestígio da literatura. Segundo Will Eisner (1999), o advento do "romance gráfico" nos anos de 1970, do qual é um dos inventores, correspondia ao nascimento de uma "nova vanguarda literária". Opinião comumente aceita e largamente difundida entre os estudiosos do meio, como prova o próprio dossiê da revista Cult já citado. Além disso, é importante apontar que as graphic novels, principalmente em seu início, nos EUA e depois no Brasil, eram publicadas por editoras especializadas na publicação de livros de literatura.

Nos últimos anos, temos visto quadrinhos de todos os tipos serem vendidos em acabamentos luxuosos em livrarias, enquanto as bancas de revista estão desaparecendo. Notamos que as principais editoras brasileiras, como a Companhia das Letras e a L\&PM, têm um seguimento dedicado exclusivamente à publicação de obras em quadrinhos. O próprio Um contrato com Deus de Will Eisner, a primeira obra auto intitulada como graphic novel, foi publicada no Brasil pela tradicional editora Brasiliense, fundada por Monteiro Lobato e Caio Prado Jr. Na década de 1980, a editora passou a investir na publicação de autores e movimentos ligados à contracultura, como Paulo Leminski e as primeiras traduções da literatura beat de Jack Kerouac e Allen Ginsberg. É nesse momento que os editores publicam Um contrato com Deus, entendendo o romance gráfico de Eisner como um desdobramento literário transgressor, similar à literatura beat e à Poesia Concreta brasileira, uma vez que a editora Brasiliense também publicara a primeira edição do livro Teoria da poesia concreta. Na capa do livro, organizado pelos poetas Décio Pignatari, Haroldo e Augusto de Campos, vemos personagens emblemáticos dos gibis, como Brucutu, Flash Gordon, Mandrake e o Amigo da Onça. Esse momento, no final da década 1970 e início de 80, é 
significativo dos quadrinhos como fenômeno literário, pelo menos sob o ponto de vista do mercado literário.

Figura 1. Capa do livro Teoria da poesia concreta
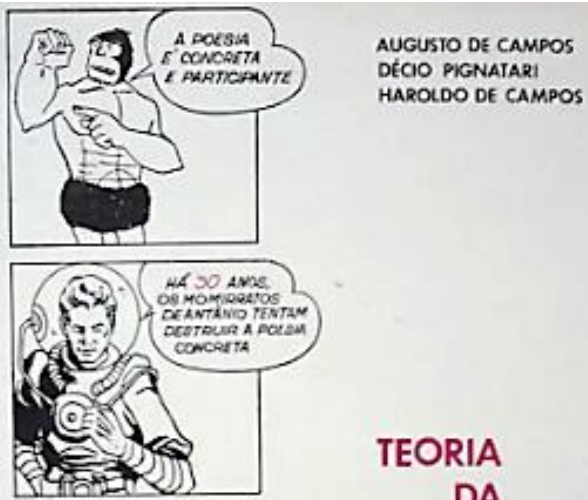

TEORIA

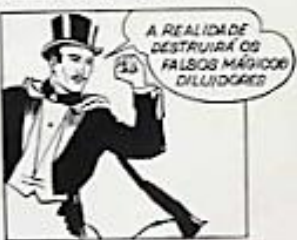

DA

POESIA

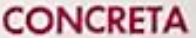

\section{TExTos CRíncos \\ E MANIFESTOS \\ 1950.1960}

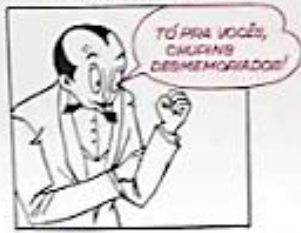

\section{brasiliense}

Fonte: Livraria Traça. ${ }^{6}$

Percebemos, hoje, uma migração dos leitores das revistas para o álbum de luxo, geralmente em capa dura, aproximando ainda mais da aparência de livro. É conhecido dos leitores o hábito de associar quadrinhos considerados "sérios" com a graphic novel, afastando 
de vez a ideia de se tratar de uma publicação para crianças. A permanência dessa nomenclatura para diferenciar as histórias consideradas "adultas" revela a peleja do meio para conquistar novos espaços.

Santiago García (2012), em Novela Gráfica7 ,que busca reexaminar a história dos quadrinhos, desde suas origens, refletindo sua relação com a literatura para compreender o termo, diz:

Certamente "novela gráfica" é apenas um termo convencional que, como costuma ocorrer, pode suscitar equívocos, pois não se deve entender que, com ele nos referimos a uma história em quadrinhos com as características formais ou narrativas de um romance literário, tampouco a um formato determinado, mas simplesmente a um tipo de HQ adulto e moderno que reclama leituras e atitudes distintas dos quadrinhos de consumo tradicional. (GARCÍA, 2012, p. 14).

Estabelece-se, portanto, uma ideia para definir os quadrinhos que, de alguma forma, apresentariam diferenciações significativas dos modelos industriais ou de fácil leitura - o que, para García, não significa uma correlação com as características do romance. Não fica claro, no entanto, do que se tratam os adjetivos "adulto" e "moderno", que exigem "leituras e atitudes distintas". Tal imprecisão de definição não é desconsiderada pelo próprio García (2012) ao longo de sua extensa pesquisa - as pertinentes reflexões do autor sobre as tentativas de nomenclaturas e suas fraquezas deixam evidentes as dificuldades de se pensar em termos absolutos. Não é raro que artistas, produtores e leitores enquadrem, sem muito critério, obras como romance gráfico, muitas vezes inserindo títulos nesse grupo a despeito de sua forma de publicação original (como aconteceu com Watchmen, originalmente uma minissérie publicada entre 1986 e 1987, hoje lido por muitos como graphic novel). As concepções podem perpassar tanto um ideal, um imaginário sobre o que é "sério" e "literário",

7 A tradução do termo em espanhol, língua original da publicação, a nosso ver, traz problemas de definição, uma vez que, em português, os termos "romance" e "novela" apresentam sentidos conceituais diferentes. Apesar de a citação respeitar a tradução, o restante do trabalho adota o termo "romance gráfico”. (NOVELA. In: MICHAELIS, Dicionário Escolar Espanhol. São Paulo: Melhoramentos.

Disponível em: https://michaelis.uol.com.br/escolar-espanhol/busca/espanhol-portugues/novela/. Acesso em: 4 jun. 2020). 
quase sempre "realista", e de como os conteúdos das obras respondem a isso, quanto apenas uma estratégia de mercado.

Figura 2. Um contrato com Deus, Will Eisner

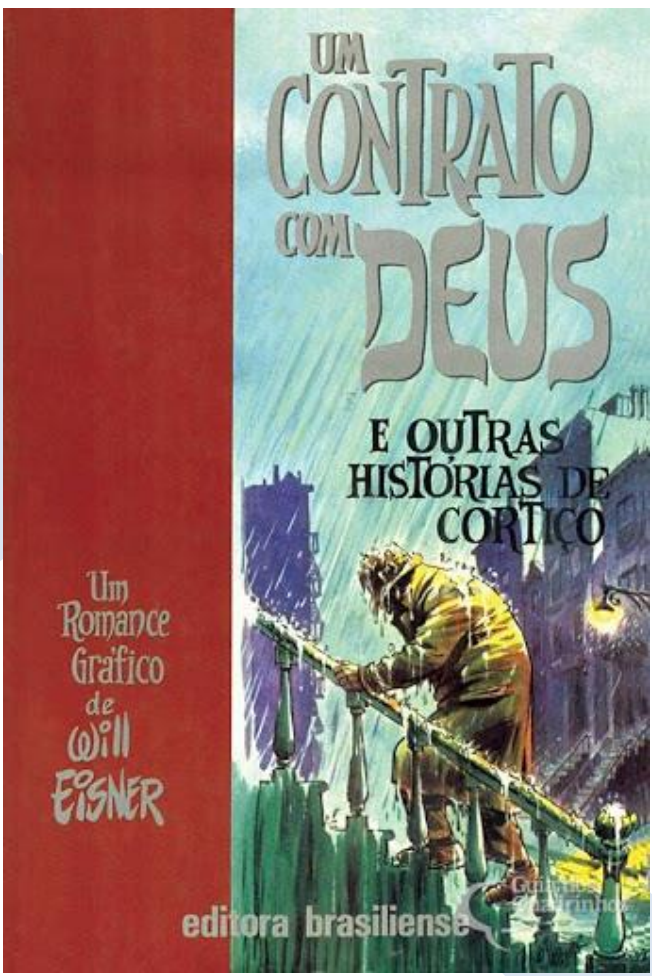

Fonte: Guia dos Quadrinhos. ${ }^{8}$

As origens do termo são incertas, mas Will Eisner, notável quadrinista norte-americano, conforme já citado, ficou conhecido como o responsável por lançar a primeira graphic novel, Um contrato com Deus, em 1978. De fato, Eisner utilizou-se do termo na capa de sua HQ para tentar vendê-la a uma editora literária, como uma estratégia de alcançar o

${ }^{8}$ Disponível em: http://www.guiadosquadrinhos.com/edicao/um-contrato-com-deus-e-outras-historias-de-cortico/um098100/28643. Acesso em 5 jul. 2020. 
público adulto (GARCÍA, 2012), mas não é exatamente uma verdade que ele fora o primeiro a usá-lo.

Waldomiro Vergueiro (2012), ao discutir sobre a legitimação do meio, aponta que o rótulo não era uma novidade:

Antes de Eisner, o termo já havia sido utilizado pelo crítico de quadrinhos norte-americano Richard Kyle, em 1964, e também por Henry Steele na revista Fantasy illustrated em 1966. Da mesma forma, o trabalho que Eisner então oferecia ao editor - Um contrato com Deus -, tampouco poderia ser considerado de fato a primeira graphic novel a ser publicada no ambiente de quadrinhos norte-americano, com diversas obras podendo ser apontadas como suas antecessoras (destacando-se, neste aspecto, Jungle Book, de Harvey Kurtzman, e Beyond Time and Again, de George Metzger, para apenas citar dois exemplos).

Por outro lado, a própria ideia compreendida pela expressão graphic novel pode ser facilmente contextualiza da em outros países, com destaque para os álbuns encadernados de histórias em quadrinhos, já naquela época correntemente publicados no ambiente europeu, em geral trazendo histórias completas de personagens consagrados, anteriormente publicadas na forma de capítulos em revistas como Tintin, Spirou ou Pilote. (VERGUEIRO, 2012, p. 25).

Graphic novel, portanto, não se resume à criação de Eisner, como também demonstra o trabalho de arqueologia do conceito presente na pesquisa de García (2012) supracitada. No entanto, Vergueiro (2012, p. 25) também ressalta que "é preciso reconhecer que Will Eisner, com seu prestígio como criador da área e inteligente atuação mercadológica, foi de capital importância para a popularização do termo e ampliação do mercado para esse tipo de publicação".

Eisner não foi responsável apenas pela popularização do rótulo, mas também pela tentativa, em seu livro Quadrinhos e Arte Sequencial, de 1985, de conceituar os quadrinhos e justificá-los como uma arte complexa com procedimentos dotados de muitas possibilidades. Sua abordagem foi um ponto de inflexão importante na relação entre os quadrinhos e o campo da literatura, uma vez que se pautou no afastamento dos conceitos do senso comum de que a nona arte era uma leitura menor. Para isso, formula o conceito de Arte Sequencial, cujo fundamento está no hibridismo entre texto e imagem. Diz: 
A configuração geral da revista de quadrinhos apresenta uma sobreposição de palavra e imagem, e, assim, é preciso que o leitor exerça as suas habilidades interpretativas visuais e verbais. As regências da arte (por exemplo, perspectiva, simetria, pincelada) e as regências da literatura (por exemplo, gramática, enredo, sintaxe) superpõem-se mutuamente. A leitura de quadrinhos é um ato de percepção estética e de esforço intelectual. (EISNER, 2010, p. 8).

O conceito considera, então, a sobreposição entre duas linguagens para compor uma. Não é sem motivo que o artista insista nos termos "leitura", "ato de percepção estética" e "esforço intelectual" (EISNER, 2010). Seu objetivo era convencer os críticos que HQs podem, sim, ser uma forma de arte complexa, pois o que era necessário para compreendê-la envolvia estar além da superficialidade. Para esse fim, precisou definir os quadrinhos como uma vertente da arte literária:

Em sua forma mais simples, os quadrinhos empregam uma série de imagens repetitivas e símbolos reconhecíveis. Quando são usados vezes e vezes para expressar ideias similares, tornam-se uma linguagem - uma forma literária, se quiserem. E é essa aplicação disciplinada que cria a "gramática" da Arte Sequencial. (EISNER, 2010, p. 8, grifo nosso).

Arte Sequencial parecia ser, para ele, a definição precisa e sintética do que os quadrinhos significavam. O termo aponta de forma autoexplicativa que os quadrinhos são mais do que apenas imagens organizadas contando uma história, mas principalmente arte, e uma forma de arte literária. Apesar de o conceito expressar a ideia de sequencialidade das imagens, há um direcionamento para a linguagem ao definir as HQs em termos essenciais - o que constitui os quadrinhos é a forma como sua composição estabelece uma gramática própria da Arte Sequencial. Ao mesmo tempo em que define quadrinhos como uma mescla das regências da arte e da literatura (portanto, uma arte híbrida), Eisner (2010) prioriza o literário ao dizer que a composição das HQs é uma "aplicação disciplinada” que gera uma gramática, uma linguagem que, se quisermos, podemos entender como uma forma literária.

Não foram apenas as teorias de Eisner (2010) que aproximaram os estudos dos quadrinhos da literatura. O próprio contexto da história das HQs já direcionava o meio 
para um tipo de publicação que aspirava reconhecimentos maiores, com obras que tratavam de temas sensíveis à sociedade. Como consequência, Maus, quadrinho sobre a experiência de um sobrevivente do holocausto, de Art Spiegelman, é premiado com o Pulitzer em 1992 (GARCÍA, 2012). Neste ponto, quadrinhos já estavam cruzando a fronteira rumo à legitimação - não mais seriam vistos como uma bobagem da indústria cultural, mas uma mídia digna de chamar a atenção de pesquisadores dos diversos campos do saber, principalmente das Letras.

Refizemos, de forma muito breve, uma parte do percurso da percepção dos quadrinhos enquanto leitura e literatura, tendo como ponto de grande relevância a participação de Eisner. A história dos quadrinhos está cheia de altos e baixos: de uma mídia ascendente e popular passou a ser julgada como lixo cultural, para depois renascer como literatura de alto prestígio. No próximo tópico, nos voltaremos para as perspectivas teóricas implicadas na associação com a abordagem literária.

\section{Tensões: arte literária ou visual?}

O campo de estudos dos quadrinhos é relativamente recente quando falamos sobre um esforço institucional que envolve departamentos, grupos de pesquisas, eventos e publicações especializadas. Há muitas disciplinas em confluência, o que resulta em diferentes abordagens. As aproximações que envolvem o campo das Letras - linguística e literária partem de pressupostos distintos, embora relacionadas. No que diz respeito ao campo literário, García (2012) identifica Eisner como forte influência. Para o autor, o quadrinista foi quem "afirmou com insistência que os quadrinhos são literatura, ideia que foi seguida com entusiasmo por muitos, entre os quais se incluem numerosos estudiosos acadêmicos da última fornada" (GARCÍA, 2012, p. 22).

Segundo o pesquisador Bart Beaty (2012), em Comics Versus Art, ao discutir as tensões entre o mundo das artes e dos quadrinhos, os estudos sobre HQs geralmente são marcados por um viés dos estudos de literatura, preocupados com questões temáticas, de gênero, além de aspectos formais e narrativos levantados por uma série de obras no domínio da cultura popular. Beaty (2012) ainda sugere que tal enfoque tem beneficiado mais os 
roteiristas do que desenhistas, contribuindo para a compreensão do quadrinho como forma literária e não como uma arte visual. O acadêmico refaz o percurso teórico norte-americano na busca de uma definição dos quadrinhos, focando em como até mesmo os mais engajados pelo meio têm evitado definir quadrinhos como uma forma de arte visual, resultando no abandono das questões estéticas em prol das temáticas, além de recair sempre nos métodos de análise literária (BEATY, 2012).

Beaty (2012), em concordância com Groensteen (2015), defende que apegar-se ao conceito de hibridismo entre imagem e texto, como propagado por Eisner (2010), sempre privilegia o aspecto literário, mais evidente. Desse modo, os quadrinhos nunca seriam vistos como uma forma de arte, mas sim uma espécie de subliteratura - que até poderia tratar de temas relevantes, apesar da sua forma. Diferentemente de Eisner (2010), os autores defendem que as HQs devem ser entendidas como uma arte cujo caráter visual é fundamental.

Em O sistema dos quadrinhos, lançado originalmente em 1999, Groensteen (2015) intenta articular um modelo instrumental de análise próprio dos quadrinhos ${ }^{9}$ que se afaste de duas práticas que, segundo o autor, não necessariamente resultam em uma compreensão produtiva. São elas:

A primeira ideia que se difunde é a seguinte: o estudo das histórias em quadrinhos, assim como de qualquer outro sistema semiótico, deve passar por uma decomposição em unidades constitutivas elementares: em "elementos mínimos intercambiáveis que possuem significado próprio", para falar como Christian Metz. Acredito que este método tem chances de revelar o que é realmente específico à linguagem das HQs.

Segunda ideia bastante difundida: que as histórias em quadrinhos seriam essencialmente um misto de texto e imagem, uma combinação específica de códigos linguísticos e visuais, um ponto de reencontro entre duas "matérias de expressão" (na acepção linguista de Louis

\footnotetext{
9 Para o autor, "faz-se necessário reconhecer como único fundamento ontológico dos quadrinhos a conexão de uma pluralidade de imagens solidárias" (GROENSTEEN, 2015, p. 27), isto é, a solidariedade icônica. A partir disso, desenvolve a ideia de um sistema, o modo como as imagens se articulam e se relacionam em uma HQ, pautando-se nos conceitos por ele propostos de artrologia e espaçotopia (GROENSTEEN, 2015). O desenvolvimento desses conceitos está além dos objetivos desse trabalho.
} 
Hjelmslev). Contrariando esta concepção, meu intento é demonstrar a primazia da imagem e, assim, a necessidade de dar uma precedência teórica que designarei, por enquanto, pelo nome genérico de "códigos visuais”. (GROENSTEEN, 2015, p. 10-11, grifos do autor).

Diz ainda que tais procedimentos respondem à tradição ocidental de se tomar o aspecto verbal como preponderante ao aspecto visual, a língua então tomada como modelo de toda linguagem, e o livro, por sua vez, de todas as formas narrativas (GROENSTEEN, 2015). Além disso, o autor ressalta como o entendimento predominante de que qualquer contemplação de uma figura representativa é uma leitura resultou na transferência de conceitos linguísticos para a análise das artes visuais.

A partir do que avalia o autor, podemos dizer que os procedimentos de análise aos quais se contrapõe partem do pressuposto de que quadrinhos podem ser entendidos, fundamentalmente, como leitura (aspectos linguísticos) e literatura. Obviamente, não há quem discorde que quadrinhos são objetos de leitura e por isso são lidos. Groensteen (2015) se opõe é à metodologia que parte da ideia de leitura como aspecto ontológico dos quadrinhos, que os aproximam dos métodos de análise da língua, isto é, decompondo seus sintagmas e estruturas aos detalhes para compreender seus sentidos. Sua crítica se direciona também ao entendimento de quadrinho como literatura - em síntese, recusa o tratamento como uma arte predominantemente literária, no sentido mais formalista do termo. Afirma:

De fato, aqueles que atribuíram ao verbal um status igualitário ao status da imagem na economia dos quadrinhos partem do princípio de que a escrita é o veículo privilegiado da narração em geral. No entanto, a multiplicidade de espécies narrativas tornou esta suposição obsoleta. (GROENSTEEN, 2015, p. 17, grifos do autor).

É evidente a rejeição de Groensteen (2015) à ideia de que associar quadrinhos à literatura seja um método eficiente de legitimá-los. Embora essa questão sequer seja posta, ao tratar dos efeitos acarretados por esse processo, que podemos chamar de parasitismo de prestígio de gênero, o autor rejeita a proposta antes mesmo de ser formulada. Fica posta a compreensão de que literatura e narrativa não se confundem e, portanto, está a tratar de outro gênero narrativo. 
Beaty (2012) vai mais longe nesse debate: partindo dos pontos abordados por Groensteen (2015), afirma que a busca por legitimação dos quadrinhos pela literatura nunca foi produtiva e os afastou de seu lugar de direito: o mundo das artes visuais. Fazer parte desse mundo significa compartilhar seus espaços de legitimação, ou seja, museus, galerias de arte e disputas dos espaços simbólicos da dita "alta cultura”. Significa, ainda, compartilhar de uma tradição e sua história, que o autor sugere estar em falta por não dialogar em igualdade com as tradições das HQs, isto é, seu cânone próprio (BEATY, 2012).

Para esses autores, analisar quadrinhos pelos paradigmas do campo das Letras resulta na compreensão da nona arte como um objeto cuja essência de sentido recai sobre o aspecto verbal. Críticos como Beaty e Groensteen deixam a entender que a busca de legitimação pela associação com a literatura simplesmente não compensa o prejuízo, pelo contrário, só aprofunda as debilidades na construção de uma disciplina própria.

Por outro lado, Charles Hatfield $(2005,2010)$, continuou advogando a ideia de quadrinho como uma forma de arte literária, em seu livro Alternative Comics: na Emerging Literature (2005). A obra gerou um debate entre o autor e Beaty, publicado na página da web The Comics Reporter (BEATY; HATFIELD, 2005). No texto, em resposta às críticas de Beaty, Hatfield defendeu que sua posição nunca passou pela questão de legitimação, mas sim por uma maneira de questionar os conceitos de literatura. Para ele, definir quadrinhos - entre outros objetos culturais - como literatura contribui para expandir a compreensão sobre o que é literatura e o que compõe o seu cânone. Beaty faz sua réplica com a seguinte questão: se tudo pode ser colocado sob o conceito de literatura, há algum propósito falar em literatura como um conceito útil? (BEATY; HATFIELD, 2005),

Nina Mickwitz (2016), em seu trabalho Documentary Comics, cuja abordagem procura uma aproximação dos quadrinhos que apresentam um relato pessoal não com a literatura, mas com o documentário, questiona a preocupação de Beaty com a questão da legitimidade pela literatura. Embora a autora admita que a categorização dos quadrinhos "de acordo com os paradigmas literários - jornalismo, autobiografia, biografia, e assim por diante mina conexões e obscurece relações que têm o potencial de enriquecer nosso entendimento tanto sobre quadrinho quanto outras expressões culturais" (MICKWITZ, 2016, p. 3, 
tradução nossa ${ }^{10}$ ), ela alega que a defesa de Beaty de quadrinho como arte visual se pauta pelo mesmo tipo de associação com a literatura, reclamando, ao invés da legitimidade literária, espaços em museus e galerias (MICKWITZ, 2016).

Artes visuais ou literatura, transparece que cada lado terá que se defender contra a tentativa de promover a legitimação do meio por associação, como se os quadrinhos precisassem de uma justificativa por ser um intruso em outros campos. Talvez o problema esteja na definição. Paulo Ramos (2012), referência na pesquisa sobre quadrinhos no Brasil, nos aponta um caminho que resolveria essa problemática. Diz:

Quadrinhos são quadrinhos. E, como tais, gozam de uma linguagem autônoma, que usa mecanismos próprios para representar os elementos narrativos. Há muitos pontos comuns com a literatura, evidentemente. Assim como há também com o cinema, o teatro e tantas outras linguagens. (RAMOS, 2010, p. 17).

Ramos (2010) sustenta uma posição mais consciente a respeito da autonomia dos quadrinhos enquanto uma forma de arte que tem sua própria linguagem. Pela sua definição, parece assumir que a questão de legitimação deve ser superada e que os quadrinhos não precisam ser defendidos. Não perde de vista, no entanto, as possibilidades interdisciplinares, já que dialogam com outras linguagens, demandando abordagens amplas.

Hatfield (2010), ao discutir sobre o caráter interdisciplinar dos estudos sobre os quadrinhos, sugere que o fato de não terem uma identidade própria enquanto disciplina pode ser uma oportunidade para que o campo seja consciente sobre isso de maneira positiva, para então produzir uma reflexão sobre seus paradigmas. A posição de Ramos, a nosso ver, reflete essa consciência, evitando os impasses causados pelas tentativas de definição como um ramo de outra disciplina. No entanto, abordagens como a de Hatfield (2005,

${ }^{10}$ Categorizing these texts according to literary paradigms - journalism, autobiography, biography, and soon - undercuts connections and obscures relationships that have the potential to enrich our understanding of both comics and other cultural expressions. 
2010) - literária - ou de Beaty (2012) - artes visuais - ajudam a rever não só o próprio objeto dos quadrinhos, mas também as matérias associadas, seus métodos e tradições.

\section{Conclusão}

O debate não parece ter alcançado um denominador comum sobre quais abordagens são mais eficazes para analisar um meio com tantas possibilidades. Definir quadrinhos como literatura pode significar muitas coisas a depender dos pressupostos que se tem sobre o que significa literatura, e o mesmo acontece com as artes visuais. Ao observar a discussão, podemos ao menos inferir que a metodologia escolhida pelo acadêmico como ferramenta de análise implica, em alguma medida, em um conceito sobre o objeto. Por vezes, para justificar não o objeto, mas a sua própria abordagem, o estudioso se vê na necessidade de defini-lo, gerando outros problemas.

Compreender os quadrinhos como um gênero próprio - não como literatura, não como artes visuais, mas como quadrinhos - pode ser uma forma de tratar a questão como superada, e uma oportunidade para refletir sua relação com outras artes "não em termos comparativos, mas em termos alternativos” (GARCÍA, 2012, p. 26). Isto é, estabelecer um campo próprio sem perder de vista seu caráter interdisciplinar.

Nesse trabalho, buscamos fazer um breve panorama sobre as certas questões que envolvem a definição dos quadrinhos como literatura e as tensões que esse debate provoca. Ao fim, apontamos uma perspectiva fora desse conflito: um campo que se sustente por si mesmo sem precisar estar na aba de qualquer outra matéria. Os estudos sobre quadrinhos são novos, ainda há muito a ser explorado, o que pode ser, talvez, um convite para muitos pesquisadores de diversas áreas.

\section{COMICS AS LITERARY PHENOMENON: PROBLEMS, IMPASSES AND CHALLENGES}

ABSTRACT: This work intends to discuss issues raised by the understanding of comic books as a
literary phenomenon. At first, we sought to understand how comics approached the field of literature,
considering Eisner's (1989) propositions about comic book narratives as sequential art and the pop-
ularization of the idea of graphic novel. Then we discuss, from theorists as Beaty (2012), Hatfield 
(2010) and Groensteen (2015), the tensions that emerge in the theoretical field, between the definition of comics as literature or visual art, and the impasses caused by the search for prestige, in addition to questions about the field of comic studies as a discipline of its own.

KEYWORDS: Comics; Graphic novel; Literature.

\section{REFERÊNCIAS}

BARBIERI, Daniele. As linguagens dos quadrinhos. Tradução: Thiago de Almeida Castor do Amaral. São Paulo: Petrópolis, 2017.

BEATY, Bart. Comics Versus Art. Toronto: University of Toronto, 2012. Versão para Kindle.

BEATY, Bart; HATFIELD, Charles. Let's You and Him Fight: Alternative Comics - an Emerging Literature. The Comics Reporter, 2005. Disponível em: https://www.comicsreporter.com/index.php/briefings/commentary/3370/. Acesso em: 10 jun. 2020.

BENJAMIN, Walter. Magia e técnica, arte e politica. São Paulo: Brasiliense, 1993.

CAMPOS, Rogério de. Imageria: o nascimento das histórias em quadrinhos. São Paulo: Veneta, 2015.

DUARTE, Renan. Quadrinhos é coisa de criança: Considerações sobre um equívoco desimportante. Literartes, v. 1, n. 8, 31 out. 2018. Disponível em:https://www.revistas.usp.br/literartes/article/view/137828. Acesso em: 10 jun. 2020.

EISNER, Will. Quadrinhos e arte sequencial. São Paulo: Martins Fontes, 1999.

GARCÍA, Santiago. A Novela Gráfica. Tradução: Magda Lopes. São Paulo: Martins Fontes, 2012.

GROENSTEEN, Thierry. O sistema dos quadrinhos. Tradução: Érico Assis. Rio de Janeiro: Marsupial, 2015.

GROENSTEEN, Thierry. Why Are Comics Still in Search of Cultural Legitimization? In: HEER, Jeet; WORCESTER, Kent. (Org.) A comics studies reader. Jackson: University Press of Mississipi, 2009. Versão Kindle.

HATFIELD, Charles. Alternative Comics: An Emerging Literature. Jackson: University Press of Mississippi, 2005.

HATFIELD, Charles. Indiscipline, or, The Condition of Comics Studies. Transatlantica. Paris, n. 1, Summer/Autumn 2010. Disponível em: https:/ /journals.openedition.org/transatlantica/4933. Acesso em: 6 jun. 2020.

MICKWITZ, Nina. Documentary Comics: Graphic Truth-Telling in a Skeptical Age. Nova York: Palgrave Macmillan, 2015. 
MOYA, Álvaro de. Era uma vez. um menino amarelo... In: (Org). Shazam! São Paulo: Perspectiva, 1970.

PINTO, Manuel da Costa. Especial quadrinhos: a ascensão do romance gráfico. CULT, São Paulo, n. 215, ago., 2016

RAMA, Angel; VERGUEIRO, Waldomiro. Como usar as histórias em quadrinhos em sala de aula. São Paulo: Contexto, 2004.

RAMOS, Paulo. A leitura dos quadrinhos. São Paulo: Contexto, 2010.

RENARD, Jean-Bruno. La bande dessinée. Paris: Editions Seghers, 1978.

SANDERS, Joe Sutliff. How comics became kid's stuff. In: ABATE, Michelle A.; SANDERS, Joe S. (Org.) Good Grief! Children and Comics. Columbus, OH: Billy Ireland Cartoon Library \&Museum, 2016. E-book. Disponível em: https://kb.osu.edu/dspace/bitstream/handle/1811/77539/BICLM_Good-Grief_6-92016.pdf?sequence=1. Acesso em: 05 jul. 2020.

VERGUEIRO, Waldomiro. As histórias em quadrinhos no limiar de novos tempos: em busca de sua legitimação como produto artístico e intelectualmente valorizado. Visualidades, v. 7, n. 1, 19 abr. 2012. Disponível em: https://doi.org/10.5216/vis.v7i1.18118. Acesso em: 8 jun. 2020.

WOOD, Mary.Origins of the Kid: Street Arabs, Slum Life, and Yellow Presses. The Yellow Kid on the paper stage - acting out class tensions and racial divisions in the new urban environment, 2004. Disponível em: http://xroads.virginia.edu/ MA04/wood/ykid/yellowkid2.htm. Acesso em: 27 jun. 2020.

Recebido em: 28/09/2020. Aprovado em: 22/10/2020. 